\title{
Integrity Analysis of the Rainwater Pump Impeller
}

\author{
Sergiu-Valentin Galatanu ${ }^{1, *}$, Sebastian Muntean ${ }^{1,2}$, Liviu Marsavina ${ }^{1}$, Dan Micota $^{1}$ \\ and Ionel Draghici ${ }^{3}$ \\ ${ }^{1}$ Politehnica University of Timisoara, 1 Mihai Viteazul Blvd., 300222, Timisoara, Romania \\ ${ }^{2}$ Romanian Academy - Timisoara Branch, 24 Mihai Viteazul Blvd., 300223, Timisoara, Romania \\ ${ }^{3}$ Aquatim S.A. Timisoara, 11/A Gheorghe Lazăr Street, 300081, Timisoara, Romania
}

\begin{abstract}
The purpose of this paper is to examine the failure problems encountered during the operation of the rainwater pump impellers installed in a wastewater station. The rainwater pumps are specially designed to operate in wastewater plants. The fibbers and wastes are discharged together with rainwater during storms with this type of pumps to avoid the flood of the wastewater station. Several problems have occurred in service due to the fibbers clog the gap between the impeller blades and the pump casing. The analysis of the catastrophic events associated to the rainwater pumps installed in a wastewater station is performed. As a result, it has been identified that the catastrophic events are due to the brittle fracture of the fasten bolts connecting the impeller blades and the pump hub, respectively. Analytical and numerical analysis were perform in order to determine the maximum shear stress on the fasten bolts. As a conclusion the partial clogging of the gap between one impeller blade and pump casing, inducing the lock of the blade and leading to catastrophic failure.
\end{abstract}

\section{Introduction}

The wastewater treatment plant (WTP) of Timisoara was design to provide services for 440000 inhabitants. The annual average volume of the wastewater treated in Timisoara's WTP is more than 42.1 million $\mathrm{m} 3$. Up to $10 \%$ of this volume is rainwater. The role of rainwater pumps is crucial because it protects the WTP from flooding under heavy rainfall, making the WTP non-operating in providing services to the population. The WTP's protection is also threatened when just two pumps, out of seven, are out of service.

Two of the seven rainwater pumps from the WTP of Timisoara suffered catastrophic damage of the impeller, requiring downtime for troubleshooting and repairs. The failures of the rainwater pumps have occurred because of fibbers clogging the gap between the impeller blades and the pump casing [1]. The reason for clogging is versatile [2-4]. Any object that fits into the municipal wastewater pipe systems can be involved $[5,6]$. The analysis of the catastrophic events associated to the rainwater pumps installed in the wastewater station has identified that the catastrophic events are due to the brittle fracture of the fastening bolts connecting the impeller blades to the pump hub, respectively.

* Corresponding author: sergiu.galatanu@upt.ro 
Galatanu et al. [7] determined the structure, mechanical properties and failure mechanism of the fibres, formed in the municipal wastewater system, that lead to the clogging up of the impeller. The results lead to the conclusion that wet fibres require a higher force for breaking, both in tensile and shearing.

The purpose of this paper is to analyse the rainwater pump impeller integrity. The paper includes an analytical calculation and numerical analyses with finite elements of the rainwater pumps required to dynamic torsion. The main conclusions are summarized in the last section.

\section{Study problems}

The impeller blade mounting solution in the hub is composed of two stainless steel bolts. The analysis of the fracture surface of the bolts indicates a brittle behaviour suggesting high mechanical stresses that exceed the resistance threshold of the material (Figures 1 and 2).

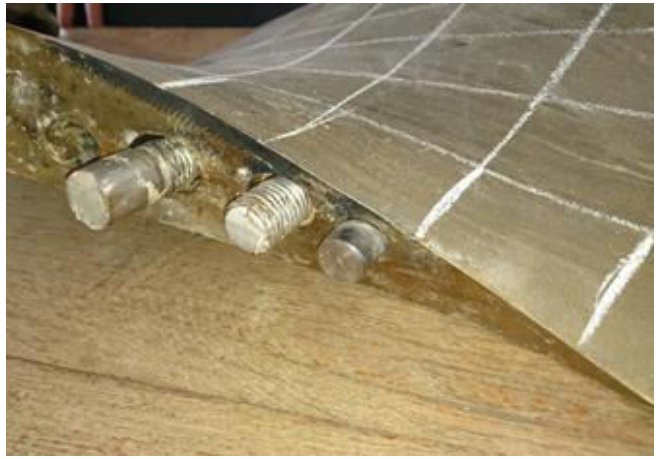

Fig. 1. Brittle behaviour of the stainless steel bolts

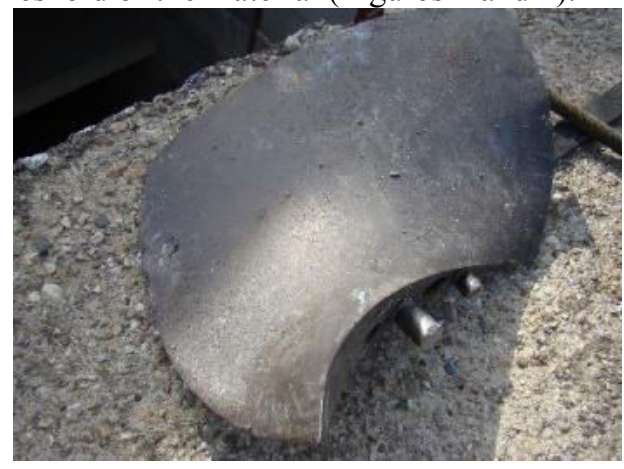

Fig. 2. The impeller blade with the 2 stainless steel bolts

The bolts are made by stainless steel 316L A4 according to ASTM, respectively 1.4401 after EN with high corrosion resistance, but low wear resistance. Table 2 shows the material characteristics of the rainwater pump components. These characteristics were used for all cases studied.

Table 1. Mechanical properties of the rainwater pump components

\begin{tabular}{|c|c|c|c|c|c|c|}
\hline $\begin{array}{c}\text { Rainwater } \\
\text { pump } \\
\text { impeller } \\
\text { components }\end{array}$ & Material & $\begin{array}{c}\text { Density } \\
{\left[\mathbf{k g} / \mathbf{m}^{3}\right]}\end{array}$ & $\begin{array}{c}\text { Young's } \\
\text { Modulus } \\
{[\mathbf{G P a}]}\end{array}$ & $\begin{array}{c}\text { Poisson's } \\
\text { Ratio }\end{array}$ & $\begin{array}{c}\text { Tensile } \\
\text { yield limit } \\
{[\mathbf{M P a}]}\end{array}$ & $\begin{array}{c}\text { Fracture } \\
\text { Strength } \\
{[\mathbf{M P a}]}\end{array}$ \\
\hline Hub & $\begin{array}{c}\text { Aluminium } \\
\text { bronze } \\
\text { CW 307G }\end{array}$ & 7580 & 120 & 0.34 & 270 & 640 \\
\hline Blades & $\begin{array}{c}\text { Austenitic } \\
\text { stainless } \\
\text { steel }\end{array}$ & 8000 & 200 & 0.31 & 640 & 800 \\
\hline Pins & $\begin{array}{c}\text { Stainless } \\
\text { steel } \\
\text { (predefined } \\
\text { by ANSYS) }\end{array}$ & 7750 & 193 & 0.31 & 207 & 586 \\
\hline
\end{tabular}

In addition to the bolts breaking, it can be observed that the blades are damaged while several cracks, failures, pinching and excessive wear are observed on it (Figure 3). The 
pump impeller is manufactured by Bronze-Aluminium alloy, which has high corrosion resistance, good hot and cold malleability, but a medium workability.

The catastrophic failure of the bolts is most likely produced in the conditions of the gap clogging between the blades and the casing because of the fibres/waste accumulated on it leading to values that exceed the strength limits of the bolts.

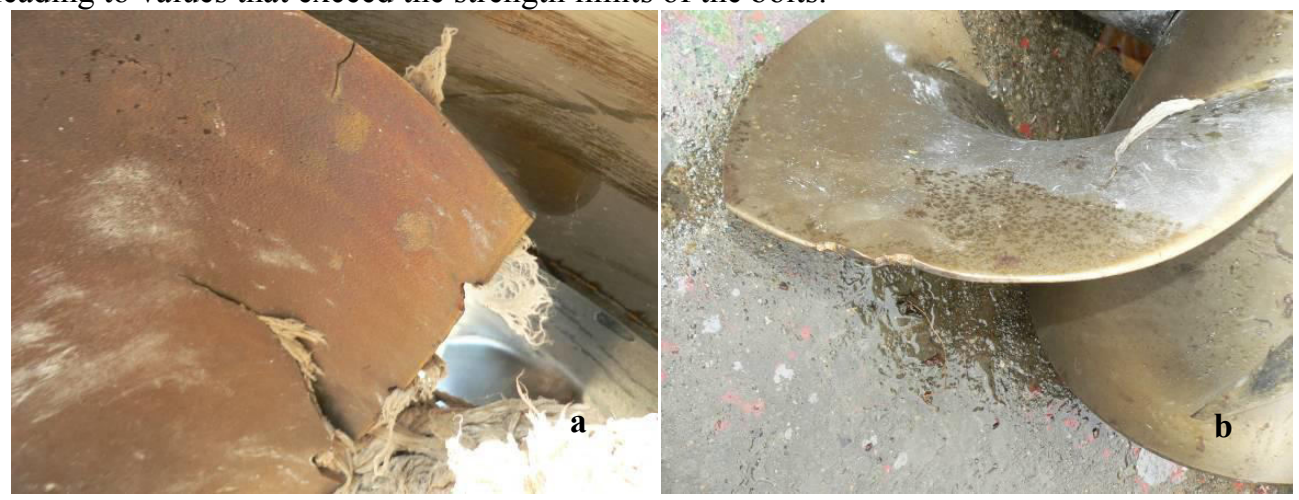

Fig. 3. Failure of the pump impeller blades: a) cracks and failure, b) pinching

\section{Analytical and numerical analysis of the rainwater pump}

This chapter focuses on the assessment of the static and dynamic torque using the finite element method applied on the rainwater pumps impeller. Firstly, the analytical calculation of the static torque was performed, taking into account the angular velocity at which the rainwater pump's rotor is subjected, in order to determine the stresses in the bolts used to mount the blades on the hub. For validation of the numerical model, simulations of the same situations where carried out and the stresses occurring in the tightening bolts and the guide pins were determined. Taking into account the validation of the numerical model from the first subchapter, in the second subchapter, a pump simulation was made considering the actual working situation, ignoring the blocking of the blades. The calculation of dynamic torque of the blocked blades are described in subchapter three.

Following scans and measurements made on the impeller blades and hub, a virtual reconstruction of the pump rotor was accomplished using CAD programs such as the geometric module in ANSYS GAMBIT, CATIA V5, the ANSYS SpaceClaim Direct modeler and the ANSYS Direct Modeler, Figure 4. After this the impeller's interior gap, the holes for the bolts and the guide pins in the hub and the blades have been modelled. ISO $4762 \mathrm{M} 24 \mathrm{x} 80$ bolts and guide pins ( $\$ 20 \mathrm{x} 40)$ were used. For numerical simulation of the rainwater pump the professional software ANSYS was used.
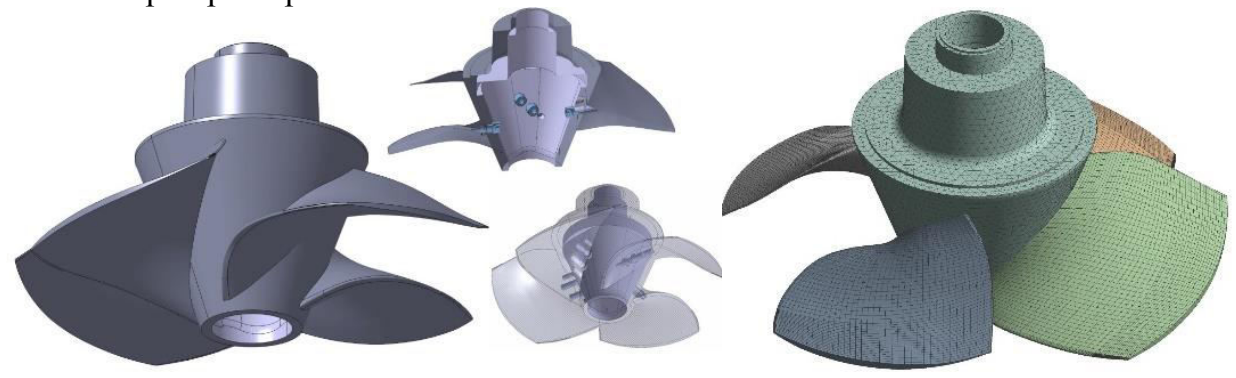

Fig. 4. 3D reconstruction

Fig. 5. Mesh of the pump impeller model of the pump impeller. 
The numerical model contains 28 contacts, which are selected either bonded or no separation, respectively. The bonded contact is selected between the threaded areas of the bolts and their respective holes in the blades to simulate the screwing and as well as between the holes in the blades and the guide pins in order to simulate the tight fit. No separation contacts were defined between the blades and the hub, also between the head of the bolts and the hub.

A mixed mesh with tetrahedral and hexahedral cells on the model is generated using secondary type elements. The tetrahedral elements have been applied on the hub of the impeller, while the hexahedral elements have been used on both bolts and pins. The mesh for the blades was done with hexahedral elements. The pump impeller model with four blades and 8 bolts and 8 pins ( 2 bolts and 2 pins on each blade) contains 159521 elements and 416064 nodes is shown in Figure 5.

\subsection{Case study 1 - Simplified loading case based only on the rotational speed}

In the first case study, both analytical calculation and numerical computation (using the finite element method) were performed in order to determine the stress in the bolts considering only the angular speed. This simplified case study is considered to assess the numerical results against analytical ones.

\section{Analytical calculation}

All 8 bolts that tighten the blades on the hub are subjected to shearing due to the torque moment transferred from the pump shaft to the impeller blades. The torque moment is associated to the nominal pump power of $\mathrm{P}=400 \mathrm{~kW}$ and the rotation speed of $\mathrm{n}=595 \mathrm{rpm}$ using next equation [8]:

$$
M_{t}=9550 \cdot \frac{P}{n}=6420.17 \mathrm{Nm}
$$

The shear force $\left(\mathrm{F}_{\mathrm{t}}\right)$ on each bolt is estimated based on this torque moment considering the same loading on all bolts:

$$
M_{t}=N \cdot \frac{F \cdot D_{\text {avg }}}{2} \Rightarrow F_{t}=\frac{2 \cdot M_{t}}{N \cdot D_{\text {avg }}}=4957.65 \mathrm{~N}
$$

where $N=8$ is the number of bolts, $D_{\text {avg }}=\left(D_{1}+D_{2}\right) / 2[\mathrm{~m}]$ is the average diameter of the bolts arrangement considered in our estimation, because the hub has a conical shape with one bolt located on the diameter of $\mathrm{D}_{1}=0.3135 \mathrm{~m}$ and another one positioned on $\mathrm{D}_{2}=0.334 \mathrm{~m}$, respectively.

To determine the shearing stress in the bolts, the shearing resistance condition is used, knowing the shearing force and the bolts diameter.

$$
\tau=\frac{F}{A}=13.05 \mathrm{MPa}
$$

The results show that the stress in the bolts is $13.05 \mathrm{MPa}$. This leads to the conclusion that when we have only the angular speed imposed on all the bodies the estimated stress value is far away below to the yield stress.

\section{Numerical simulation}

The boundary conditions imposed on the numerical model for this case are as follow: the angular speed of $62.31 \mathrm{rad} / \mathrm{s}$ corresponding to a rotation speed of $595 \mathrm{rpm}$ and the 
cylindrical support of the impeller, with only the tangential component left free to simulate the rotational bearing.

The maximum shear stress distribution on the bolts, Figure 6, and the total deformation distribution on the pump impeller, Figure 7, are plotted for this loading case.

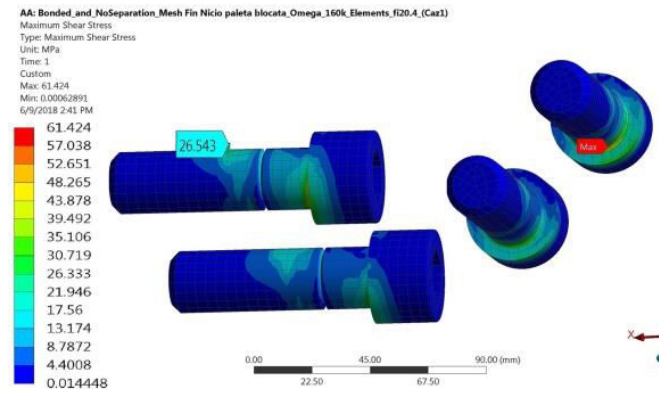

Fig. 6. Maximum shear stress on the bolts determined for the loading case 1 .

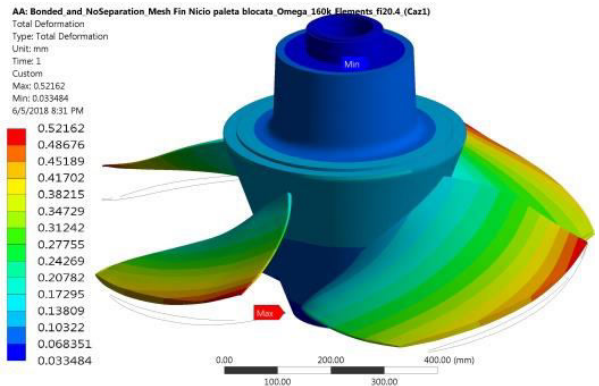

Fig. 7. Total deformation determined on the pump impeller model for the loading case 1 .

The maximum shear stress of $61.4 \mathrm{MPa}$ was obtained on the bolt located near to the leading edge of the impeller blade. This value is one order of magnitude below to the yield limit of $640 \mathrm{MPa}$. As it is expected, the maximum total deformation of $0.522 \mathrm{~mm}$ was obtained on the tip of the impeller blades near to the leading edge (red strip in Figure 8) while the maximum radial deformation value of $0.462 \mathrm{~mm}$ is determined for this loading case diminishing the gap between the blade and the pump casing with more than $15 \%$.

The maximum value of the analytical shear stress of $13.05 \mathrm{MPa}$ is determined taking into account the torque moment being estimated based on power at the nominal speed rotation, eq. (1). The maximum shear stress of $26.54 \mathrm{MPa}$ is obtained using numerical investigation on the bolt surface at the stress concentration generated by the ending of the screw. One can observe that the maximum numerical value of the shear stress is more than two times larger with respect to the analytical one. This discrepancy is associated to the hypothesis considered in analytical calculus: (i) the average diameter of the bolts arrangement; (ii) the loading is uniform applied on all bolts; (iii) the stress concentration due to the ending of the screw is not taken into account.

\subsection{Case study 2 - Loading under the pump operating conditions}

Taking into account the validation of the numerical model from the first case study, a pump simulation was performed considering the nominal operating conditions.

The boundary conditions imposed on the numerical model are: the angular speed of $62.31 \mathrm{rad} / \mathrm{s}$, the cylindrical support of the impeller, with only the tangential component left free, the gravity of $g=9.8 \mathrm{~m} / \mathrm{s}^{2}$, the pressure distribution of $0.095 \mathrm{MPa}$ corresponding to the water column on each blade and the pressure distribution exerted by the hydrodynamic force of $0.1 \mathrm{MPa}$.

The main results obtained in this case study are shown in Figures 8 and 9, respectively. Both maximum shear stress value of $68.673 \mathrm{MPa}$ and the maximum principal stress value of $223.71 \mathrm{MPa}$ was obtained on the bolt surface located in vicinity of the leading edge. The maximum value of $0.637 \mathrm{~mm}$ of the total deformation was obtained on the impeller blades in the same position as in previous case study and the maximum radial deformation value is $0.573 \mathrm{~mm}$ corresponds to a gap decreasing between the blade and the pump casing with up to $20 \%$. 


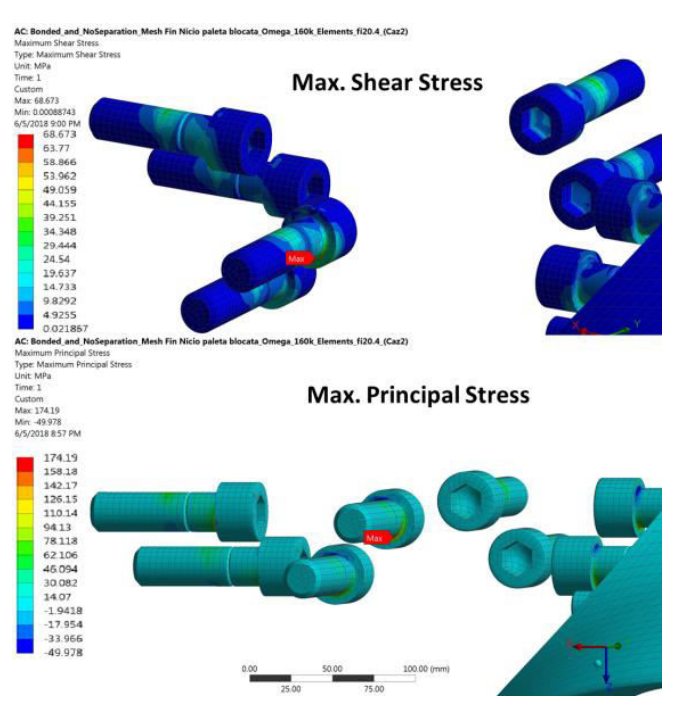

Fig. 8. Maximum shear stress distribution (up) and the maximum principal stress distribution (down) on the surface bolts for the loading case 2 .

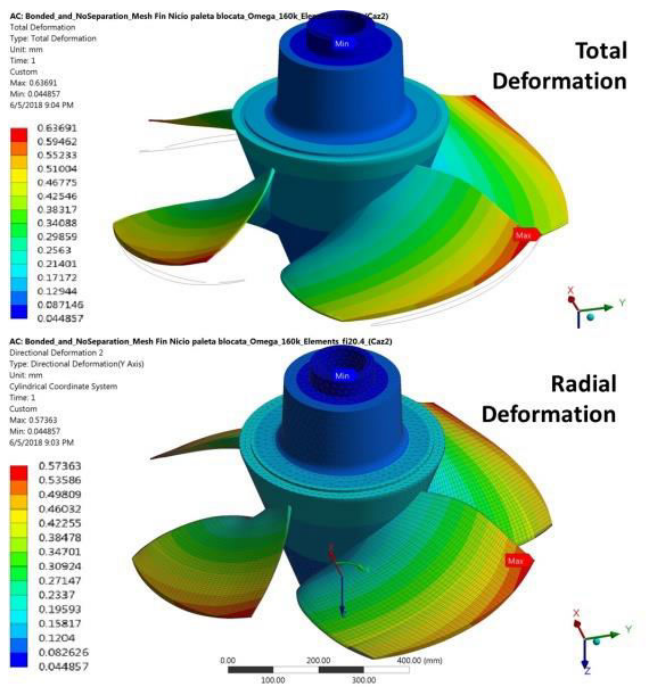

Fig. 9. Total deformation distribution (up) and the radial deformation distribution (down) on the pump impeller model for the loading case 2 .

\subsection{Case study 3 - Dynamic clogging of one impeller blade}

This case investigates the clog conditions produced by fibres which block the gap between one impeller blade and the pump casing.

The analytical calculus is performed based on rotating lock of one impeller blade. The energy conservation law is used to analytically estimate the dynamic torque of the rainwater pump $[9,10]$. The suddenly stop of motion elements constitute a dynamic phenomenon, which assumes transformation of the kinetic energy $\left(E_{c}\right)$ of the rotating parts of the rainwater pump in the deformation energy of its parts $(\mathrm{U})$. The energy conservation law is given by eq. (4) considering negligible energy losses:

$$
E_{c, \max }=U_{\max }
$$

where $E_{c}=J \omega^{2} / 2$ is the kinetic energy corresponding to the entire rotational assembly of the rainwater pump, $\mathrm{J}\left[\mathrm{N} \mathrm{s}^{2} \mathrm{~mm}\right]$ is the moment of mechanical inertia and $\omega$ is the angular speed.

The kinetic energy was estimated taking into account the angular speed $\omega$ of the rotating parts and the moment of mechanical inertia of the rotating assembly $\mathbf{J}$ with respect to the axis of the pump unit. The moment of mechanical inertia is determined using eq. (5):

$$
J_{i} \cong \frac{Q_{i} R_{i}^{2}}{2}
$$

where $\mathrm{R}$ is the radius of the components of the assembly and Q represents their weight for each rotating part. In our case, the rotating parts are the following: impeller with four blades, hub, shaft and electrical rotor.

Deformation energy is given by the formula:

$$
U=\frac{1}{2} \int_{L} \frac{M_{t}^{2} \cdot d x}{G_{i} I_{p, i}}=\frac{1}{2} M_{t}^{2} \cdot \frac{1}{k_{i}^{t}}
$$


where $\mathrm{k}_{\mathrm{i}}^{\mathrm{t}}$ is torsional stiffness coefficient of the assembly components, $\mathrm{L}_{\mathrm{i}}[\mathrm{mm}]$ is the length, $\mathrm{G}_{\mathrm{i}}[\mathrm{MPa}]$ is the shear modulus and $\mathrm{I}_{\mathrm{p}, \mathrm{i}}\left[\mathrm{mm}^{4}\right]$ is the polar moment of inertia.

$$
k_{i}^{t}=\frac{1}{\int_{L} \frac{d x}{G_{i} I_{p, i}}}
$$

Equalizing the eq. 4 and eq. 6 was obtained:

$$
M_{t}=\omega \sqrt{\sum_{i}\left(U_{i} \cdot k_{i}^{t}\right)}
$$

Consequently, the moment of torsion is $\mathrm{M}_{\mathrm{t}}=9392.96 \mathrm{kNm}$.

The stress in the fastening bolts between hub and blade is estimated with following relation:

$$
\tau=\frac{2 M_{t}}{N D_{m e d} A_{e f}}
$$

where $\mathrm{N}=2$ is the number of fastening bolts for each blade, $\mathrm{D}_{\mathrm{avg}}=0.32375 \mathrm{~m}$ represents the average diameter of the bolts arrangement. The estimated stress on each fastening bolt is equal with $\tau=76362.13 \mathrm{MPa}$.

One can observe that the maximum shear stress on each fastening bolt is approximately 85 times larger than the shear strength of $\tau_{\mathrm{r}}=800 \mathrm{MPa}$ if the entire rotating assembly of the rainwater pump is suddenly blocked. This leads to the conclusion that clogging of the clearance area between the impeller blades and the pump casing causes breaking of the fastening bolts. However, the clogging process is gradually developed covering only partial volume of the gap between tip blade and the pump casing. As a result, the catastrophic failure is produced at lower torque moment value when the gap is clogged up to $20-25 \%$.

\section{Conclusion}

The failure of rainwater pomp was investigated. Three case studies were considered: simplified loading case based only on the rotational speed, loading under the pump operating conditions and dynamic clogging of one impeller blade.

The simplified loading case based only on the rotational speed was performed in order to assess the numerical model compering with the analytical results of maximum shear stress on the bolts. It was observed that the maximum numerical value of the shear stress is more than two times larger with respect to the analytical one because of the hypothesis considered in analytical calculus.

Taking into account the validation of the numerical model from the first case study in the second case a simulation of the loading under the pump operating conditions was perform. It was shown that de total deformation corresponds to a gap decreasing between the blade and the pump casing with up to $20 \%$.

Case study no. 3 is focused on dynamic locking of one impeller blade investigating the failure conditions produced by fibres. This case corresponds to full clog of the gap between one impeller blade and the pump casing. It was obtained that the maximum shear stress is very high with respect to the shear strength of the bolt material. However, the clogging process is gradually developed covering only partial volume of the gap between tip blade and the pump casing. As a result, the catastrophic failure is produced at lower torque moment value when the gap is clogged up to $20-25 \%$.

In the future, different solution can be explored to reduce the maintenance cost and to extend the lifetime of the rainwater pumps. The use of Variable Speed Drives (VSD) on 
rainwater pumps is one solution to control reversals of direction in order to help free blocked impellers [3].

\section{Acknowledgements}

The authors are gratefully for the financial support of Bridge Grant TANAGRA/63BG2016 project code PN-III-P2-2.1-BG-2016-0082 entitled "Transfer of knowledge to the economic operator" financed by the Romanian Government and also for the support of Municipal Water Company AQUATIM SA Timişoara.

\section{References}

[1] S. Muntean, A. Bosioc, L. Marşavina, S.V. Galaţanu, I. Drăghici, L.E. Anton, 29th IAHR Symposium on Hydraulic Machinery and Systems (IAHR2018), September 16 - 21, 2018, Kyoto, Japan. (accepted)

[2] K. Höchel, P.U. Thamsen, H. Rauwald, World Pumps, 6:30-33, 2013.

[3] G. Moore, World Pumps, 6:26-33, 2011.

[4] *** Clogging: not just throughlet size, World Pumps, 9:34-38, 2012.

[5] S. Gerlach, R. Ugarelli, P.U. Thamsen, Hawaii, Honolulu April 10-15 2016.

[6] M. Isono, M. Nohmi, H. Uchida1, M. Kawai, H. Kudo, T. Kawahara, K. Miyagawa, S. Saito, IOP Conf. Ser.: Earth Environ. Sci., 22, 012009:1-11, 2014.

[7] S.V. Galaţanu, L. Marşavina, S. Muntean, D. Micota, AMS 2018 / The 7th International Conference on Advanced Materials and Structures 28th - 31th March 2018, Timisoara, Romania.

[8] G. Buzdugan,

Ed. Academiei,

Bucharest,

1991 (in Romanian).

[9] N. Posea, Al. Anghel, I. Popa, Ed. Didactica si Pedagogica, ISBN 973-30-2893-2, Bucharest, 1994 (in Romanian).

[10] I. Deutsch, Ed. Didactica si Pedagogica, Bucharest, 1979 (in Romanian). 